\title{
Pathology of the rectal wall in solitary rectal ulcer syndrome and complete rectal prolapse
}

\author{
Y S Kang, M A Kamm, A F Engel, I C Talbot
}

\begin{abstract}
Background-The aetiology and pathology of rectal prolapse and solitary rectal ulcer are poorly understood. Aims-To examine the full thickness rectal wall in these two conditions. Methods-The pathological abnormalities in the surgically resected rectal wall were studied from nine patients with solitary rectal ulcer syndrome, 11 complete rectal prolapse, and nine cancer controls. Routine haematoxylin and eosin and Van Gieson staining for collagen were performed.

Results-The rectal wall from solitary rectal ulcer syndrome specimens was thickened compared with complete rectal prolapse and controls. The major difference was in the muscularis propria $(2.2 v$ $1.1 v 1.2 \mathrm{~mm}$, medians, $\mathrm{p}<0.005)$ and particularly the inner circular muscular layer, and to a lesser extent the submucosal and outer longitudinal muscular layers. Some solitary rectal ulcer syndrome specimens showed unique features such as decussation of the two muscular layers (four of nine), nodular induration of inner circular layer (four of nine) and grouping of outer longitudinal layer into bundles (three of nine); these were not seen in complete rectal prolapse or control specimens.

Conclusions-These features, which resemble the features of high pressure sphincter tissue, may be of aetiological importance, and suggest a different pathogenesis for these two disorders. Excess collagen was seen in both disorders, was more severe in solitary rectal ulcer syndrome specimens, and probably reflects a response to repeated trauma. (Gut 1996; 38: 587-590)
\end{abstract}

Keywords: rectal wall, rectal prolapse, solitary rectal ulcer syndrome.

Madigan and Morson first described the histological features of solitary rectal ulcer syndrome in $1969,{ }^{1}$ but this description was confined to the mucosal and submucosal layers of the rectum, as might be easily taken by mucosal biopsy. The mucosal abnormalities in solitary rectal ulcer syndrome and complete rectal prolapse are now well characterised. ${ }^{2-5}$ In solitary rectal ulcer syndrome there is mucosal thickening with oedema of the lamina propria, a variable degree of fibrosis, and extension of smooth muscle fibres upwards between the crypts. The muscularis mucosa is usually hypertrophied. In complete rectal prolapse the features are histologically similar but usually less well developed. Possible abnormalities of the muscularis propria have not been investigated in either condition.

Studying the rectal wall in these conditions may help elucidate the pathogenesis of these disorders. It may also help resolve the question as to whether these two disorders are separate conditions, or two disorders on the same disease spectrum. ${ }^{3-8}$

\section{Methods}

Our pathology records were examined to identify 13 specimens of rectum that had been surgically resected at St Mark's Hospital for solitary rectal ulcer. Four were excluded because the patients had previous operations (two rectopexy, one Delorme's operation, one rectal excision), leaving nine specimens (all female patients, mean age 34, range 21-64) in this study (Table I).

Six rectal specimens from patients who had undergone rectosigmoid resection for complete rectal prolapse ${ }^{9}$ were also examined. Four rectosigmoid specimens from patients have a low anterior resection, and one specimen from a perineal rectosigmoidectomy, ${ }^{10}$ all for complete prolapse, were also examined. A total of 11 rectal specimens (nine female patients, mean age 32, range 19-89) from patients who had complete rectal prolapse were therefore examined.

Control specimens of rectum were derived from nine patients (two female, mean age 58, range 39-72) having a low anterior resection for non-obstructing cancer.

Because the operations carried out for rectal prolapse were different to those performed for solitary rectal ulcer or cancer, blocks from the high rectum were available in seven of the rectal prolapse patients, three from the midrectum and one from low rectum. All the sections from rectal cancer were taken from the mid-rectum.

Blocks from the full thickness of rectum at the site of solitary rectal ulcer and from distal resection lines for rectal prolapse and rectal cancer were recut and stained with Van Gieson

\begin{tabular}{|c|c|c|c|c|}
\hline Characteristics & Group & $\begin{array}{l}\text { Solitary rectal } \\
\text { ulcer }\end{array}$ & $\begin{array}{l}\text { Complete rectal } \\
\text { prolapse }\end{array}$ & $\begin{array}{l}\text { Rectal cancer } \\
\text { (controls) }\end{array}$ \\
\hline \multicolumn{2}{|c|}{$\begin{array}{l}\text { Age (median and range) } \\
\text { Sex (male:female) }\end{array}$} & $\begin{array}{l}34(21-64) \\
0: 9\end{array}$ & $\begin{array}{l}32(19-89) \\
2: 9\end{array}$ & $\begin{array}{l}58(39-72) \\
7: 2\end{array}$ \\
\hline Site examined & High rectum & - & 7 & 0 \\
\hline \multirow[t]{2}{*}{ histologically } & Mid-rectum & 4 & 3 & 9 \\
\hline & Low rectum & 5 & 1 & 0 \\
\hline Total number & & 9 & 11 & 9 \\
\hline
\end{tabular}


TABLE II Thickness of each rectal wall layer (median and range) in solitary rectal ulcer, complete rectal prolapse and rectal cancer controls

\begin{tabular}{|c|c|c|c|}
\hline Rectal layer Group & $\begin{array}{l}\text { Solitary rectal ulcer } \\
(n=9)\end{array}$ & $\begin{array}{l}\text { Complete rectal prolapse } \\
(n=11)\end{array}$ & $\begin{array}{l}\text { Rectal cancer (controls) } \\
(n=9)\end{array}$ \\
\hline $\begin{array}{l}\text { Submucosal layer (mm) } \\
\text { Muscularis propria (mm) } \\
\text { Inner circular (mm) } \\
\text { Outer longitudinal (mm) }\end{array}$ & $\begin{array}{l}1 \cdot 4(0 \cdot 4-2 \cdot 8) \\
2 \cdot 2(1 \cdot 4-5 \cdot 5) \\
1 \cdot 1(0 \cdot 6-3 \cdot 0) \\
1 \cdot 3(0 \cdot 5-2 \cdot 5)\end{array}$ & $\begin{array}{l}0.8(0.4-1 \cdot 2)^{\star} \\
1 \cdot 1(0.7-2 \cdot 5) \dagger \\
0.7(0.4-1 \cdot 4) \dagger \\
0.7(0.3-1 \cdot 8)^{\star}\end{array}$ & $\begin{array}{l}0.7(0.3-1 \cdot 1) \\
1.2(0.7-1 \cdot 8) \dagger \\
0.6(0.3-1.0) \dagger \\
0.6(0.3-0.9)^{\star}\end{array}$ \\
\hline
\end{tabular}

${ }^{\star} \mathrm{p}<0.05$ when compared with solitary rectal ulcer;

$\mathrm{tp}<0.005$ when compared with solitary rectal ulcer.

stain for collagen content. These were examined in conjunction with the original haematoxylin and eosin stain. Blocks from rectal cancer specimens were taken several centimetres away from the tumour.

One slide for each patient was examined, and the measurements were taken using the micrometre scale on the microscope stage.

\section{Histological examination}

The thickness of submucosa, inner circular muscular layer, and outer longitudinal muscular layer were measured in millimetres. The collagen content was quantified into three different grades: $1=$ normal, $2=$ mild or moderate collagen excess, and $3=$ severe collagen excess.

The Mann-Whitney U test was used to compare the thickness of each layer of rectal wall between solitary rectal ulcer and rectal prolapse, between solitary rectal ulcer and controls, and between rectal prolapse and controls.

\section{Results}

Table II shows the thicknesses of the submucosal layer, inner circular muscular layer, outer longitudinal layer, and muscularis propria as a whole in solitary rectal ulcer, complete rectal prolapse, and rectal cancer. The rectal wall from solitary rectal ulcer specimens was significantly thicker compared with that of complete rectal prolapse and rectal cancer specimens. Solitary rectal ulcer differed significantly for both rectal prolapse and the rectum in cancer patients in thickness of muscularis propria $(\mathrm{p}<0.005)$, particularly of the inner circular layer $(p<0.005)$ (Figs $1,2,3)$. The outer longitudinal layer was only slightly thicker in solitary rectal ulcer than in the outer two situations $(0.02<\mathrm{p}<0.05)$. The

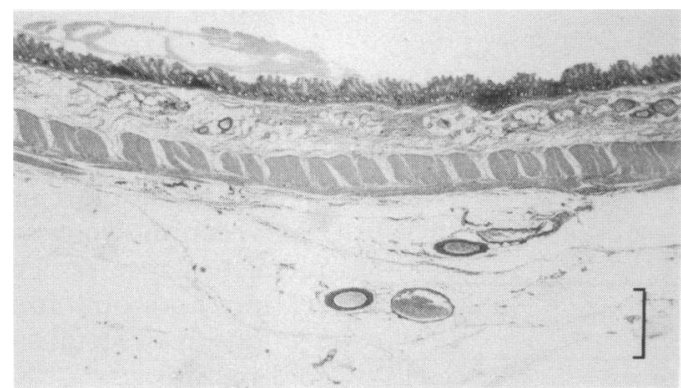

Figure 1: Histological examination of normal rectum derived from a patient having cancer surgery. The relative thickness of both muscle coats in the muscularis propria is apparent. (Bar $=1 \mathrm{~mm}$, longitudinal section, haematoxylin and eosin $\times 12$ ).

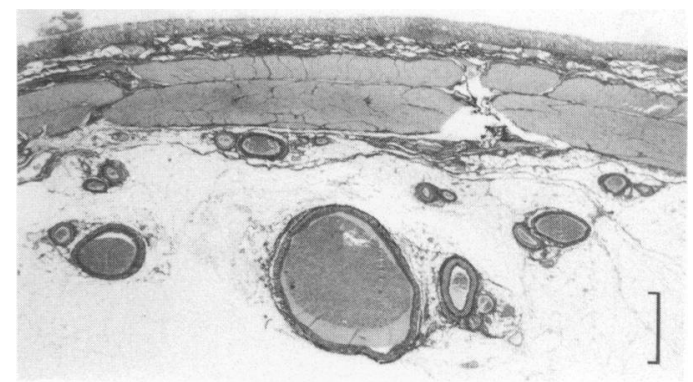

Figure 2: Histological examination of the rectum in a patient with complete rectal prolapse. Both layers of the muscularis propria are thickened. (Bar=1 $\mathrm{mm}$, longitudinal section, haematoxylin and eosin $\times 12$ ).

submucosa was only marginally thicker in solitary rectal ulcer compared with rectal prolapse $(p=0.05)$ and rectal cancer controls $(p=0.06)$.

In solitary rectal ulcer the muscularis propria ranged in thickness from $1.4 \mathrm{~mm}$ to $5.5 \mathrm{~mm}$ and six of nine specimens showed thickening greater than $2 \mathrm{~mm}$, regarded as its maximum normal thickness in the rectum. ${ }^{11}$ In contrast, only two of 11 complete rectal prolapse specimens and none of the nine rectums removed for cancer showed thickening of muscularis propria greater than $2 \mathrm{~mm}$.

Table III shows the collagen content of each layer in each group. Solitary rectal ulcer specimens showed considerable increase of collagen content in both the submucosal layer and the muscularis propria. Complete rectal prolapse specimens also showed increased collagen content but this was less noticeable than in solitary rectal ulcer specimens.

An additional histological feature was decussation of inner circular and outer longitudinal muscular layers and nodular bands in the inner circular layer. This was seen in four of nine solitary rectal ulcer specimens (Fig 3). An additional finding was grouping of the outer longitudinal muscle layer into bundles in three solitary rectal ulcer specimens, so they looked similar to the structure normally present in the internal anal sphincter (Fig 3). None of these findings were seen in complete rectal prolapse or rectal cancer specimens.

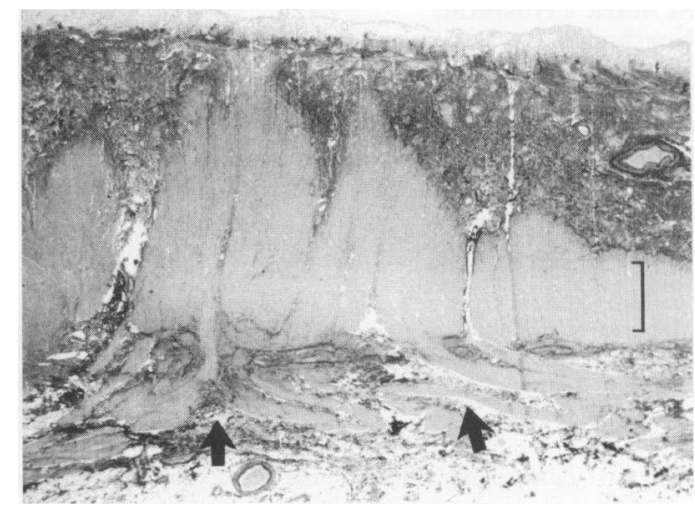

Figure 3: Longitudinal section of the rectal wall from a patient with solitary rectal ulcer syndrome. The circular muscle is thickened but also extends up towards the mucosa. In addition the longitudinal muscle has an unusual appearance of muscle group decussation (arrow), apparently merging with the circular muscle in places (arrow). This is similar to the appearance of smooth muscle seen in the normal internal anal sphincter. (Bar=1 mm, haematoxylin and eosin $\times 12$ ). 
TABLE III Amount of collagen (grade) in each layer of rectal wall in solitary rectal ulcer, complete rectal prolapse, and rectal cancer controls

\begin{tabular}{|c|c|c|c|c|c|c|}
\hline \multirow{2}{*}{$\begin{array}{l}\begin{array}{l}\text { Degree of } \\
\text { collagen } \\
\text { amount }\end{array} \\
\text { amount }\end{array}$} & \multicolumn{3}{|c|}{ Submucosal layer } & \multicolumn{3}{|c|}{ Muscularis propria layer } \\
\hline & $\begin{array}{l}\text { Solitary } \\
\text { rectal } \\
\text { ulcer }\end{array}$ & $\begin{array}{l}\text { Complete } \\
\text { rectal } \\
\text { prolapse }\end{array}$ & $\begin{array}{l}\text { Rectal } \\
\text { cancer } \\
\text { (controls) }\end{array}$ & $\begin{array}{l}\text { Solitary } \\
\text { rectal } \\
\text { ulcer }\end{array}$ & $\begin{array}{l}\text { Complete } \\
\text { rectal } \\
\text { prolapse }\end{array}$ & $\begin{array}{l}\text { Rectal } \\
\text { cancer } \\
\text { (controls) }\end{array}$ \\
\hline Grade 1 & - & 3 & 9 & 3 & 7 & 9 \\
\hline Grade 2 & 5 & 8 & 0 & 4 & 4 & 0 \\
\hline Grade 3 & 4 & 0 & 0 & 2 & 0 & 0 \\
\hline Total number & 9 & 11 & 9 & 9 & 11 & 9 \\
\hline
\end{tabular}

Grade 1: normal collagen amount, grade 2: mild or moderate collagen excess, grade 3: severe collagen excess. the cause of the muscle hypertrophy in patients with a solitary rectal ulcer. They also postulated that a chronically exaggerated muscular effort of pushing against the barrier of a tense puborectalis muscle could be one of the mechanisms of the enlargement of the muscularis propria in their patients. ${ }^{11}$ However, although muscular hypertrophy of the bowel wall can sometimes be seen in chronic obstruction such as idiopathic megacolon, ${ }^{14}$ we believe that an inappropriately contracted sphincter muscle is unlikely to act as sufficient a distal obstruction to produce the observed changes. Inappropriate sphincter contraction is seen in only about $50 \%$ of solitary rectal ulcer patients. ${ }^{415}$ Whether the severe straining seen in this syndrome causes the muscular hypertrophy is unknown.

It is possible that the symptom of constant urge, which is peculiar to solitary rectal ulcer, induces secondary hypertrophy of the muscularis propria of the rectal wall by encouraging active contraction of the rectum. ${ }^{7}$ Alternatively it may be a secondary symptom stimulated by the hyperactivity of already hypertrophied muscular layers caused by some other mechanism.

Four of our patients with solitary rectal ulcer showed structural changes in the muscularis propria similar to the normal structure of the internal anal sphincter (decussation of circular with longitudinal fibres and grouping of smooth muscle fibres into bundles). This suggests that in established solitary rectal ulcer, a segment of the affected part of the mid or upper rectum may be acting as an aberrant high pressure zone high in the rectum. This may be of aetiological importance.

Histological examination of the rectal wall in complete rectal prolapse was unremarkable, suggesting that the primary pathology may not lie in the wall itself but rather in its supporting structures.

In conclusion, it is evident that the pathogenesis of solitary rectal ulcer is probably related to factors within the rectal wall itself and is different from that of rectal prolapse, which is the result of external anatomical factors such as intussusception. ${ }^{15}$ Differences in the thickness and structure of the rectal wall in these two conditions are consistent with distinct differences in their underlying mechanisms. Finally, it is probable that the increase in collagen content in these disorders represents a process of repair after longstanding trauma.

1 Madigan MR, Morson BC. Solitary ulcer of the rectum. Gut 1969; 10: 871-81.

2 Rutter KRP. Solitary ulcer syndrome of the rectum: its relation to mucosal prolapse. In: Henry MM, Swash M, eds. Coloproctology and the pelvic floor. Pathophysiology and management. London: Butterworths, 1985: 282-98.

3 Mackle EJ, Parks TG. The pathogenesis and pathophysiology of rectal prolapse and solitary rectal ulcer synphysiology of rectal prolapse and solitary rectal

4 Nicholls RJ. Rectal prolapse and the solitary ulcer synicholls RJ. Rectal prolapse and the solitary ulcer syndrome. In: Kamm MA, Lennard-Jones JE, eds. Constipation. Peters

5 Rutter KRP, Riddell RH. The solitary ulcer syndrome of the Rutter KRP, Riddell RH. The solitary ulcer sy
rectum. Clin Gastroenterol 1975; 4: 505-30.

6 Womack NR, Williams NS, Holmfield JHM, Morrison JFB. Pressure and prolapse - the cause of solitary rectal ulceraPressure and prolapse - the caus
tion. Gut 1987; 28: 1228-33.

7 Sun WM, Read NW, Donelly TC, Bannister JJ, Shorthouse 
AJ. A common pathophysiology for full thickness rectal prolapse, anterior-mucosal-prolapse and solitary rectal ulcer. Br f Surg 1989; 76: 290-5.

8 Ford MJ, Anderson JR, Gilmour HM, Holt S, Sircus W, Heading RC. Clinical spectrum of solitary ulcer syndrome of the rectum. Gastroenterology 1983; 84: 1533-40.

9 Frykman HM, Goldberg SM. The surgical treatment of rectal procidentia. Surg Gynecol Obstet 1969; 129: 1225-30.

10 Altemeier WA, Cuthbertson WR, Schowengerdt C, Hunt J. Nineteen years experience with one-stage perineal repair
Nint of rectal prolapse. Ann Surg 1971; 173: 993-1006.

11 Van Outryve MJ, Pelckmans PA, Fierens H, Van Maercke YM. Transrectal ultrasound study of the pathogenesis of solitary rectal ulcer syndrome. Gut 1993; 34: 1422-6.
12 Jass JR. The large intestine. In: Morson BC, ed. Systemic pathology: alimentary tract. Vol 3. 3rd ed. Edinburgh: Churchill Livingstone, 1987: 313-95.

13 Devadhar DSC. Surgical correction of rectal procidentia. Surgery 1967; 62: 847-52.

14 Gattuso JM, Talbot IC, Kamm MA. Pathology of idiopathic megarectum and megacolon. In: Kamm MA Lennard-Jones JE, eds. Constipation. Petersfield, UK: Wrightson Biomedical Publishing, 1994: 213-8. WK: Wrightson Biomedical Publishing,

15 Broden B, Snellman B. Procidentia of the rectum studied with cineradiography: a contribution to the discussion of causative mechanism. Dis Colon Rectum 1968; 11: 330-47. 